\title{
Premature rupture of Membrane : Maternal and neonatal approach
}

\author{
Original \\ Ahmed M Abdelghany ${ }^{1}$, Samir Mohammed Mounir ${ }^{2}$ \\ Article \\ ${ }^{1}$ Departments of Obstetrics and Gynecology, ${ }^{2}$ Pediatric, Minia University, Minia, Egypt
}

\begin{abstract}
Aim of work: To determine bacterial causative organisms of premature rupture of membrane (PROM) and its detrimental effect on maternal and neonatal outcome.

Patients and Methods: This study included 150 pregnant females at gestational age between 28 up to39 weeks who were followed up from onset of PROM till two weeks after delivery. The study included females. High vaginal swab and amniotic fluid sample were taken for culture and sensitivity. The outcome measures were the prevalence of genital tract bacterial infection, in addition to fetal and maternal complication in swab +ve patients.

Results: The mean age was $27.7 \pm 4.69$ years ranged between 19-38 years, with mean gestational age of $34.81 \pm 2.7$ weeks. Ninety patients $(60 \%)$ were swab +ve and 60 patients $(40 \%)$ were -ve cultured results. There was a significant increase in cases with positive culture results in neonatal sepsis, prematurity and early neonatal death (END). The most common organism were G(B) Beta hemolytic streptococci in mothers with Chorioamnionitis and G(A)Beta hemolytic streptococci in puerperal sepsis. The most commonest organism founded in swab +ve cases with neonatal sepsis was Coagulase -ve Staph, while it was G(b) StreptAglactiae was in premature cases, E-coli in incubated neonates, and non-hemolytic streptococci organism in cases with END.

Conclusion: The screening of the vaginal infections in patients complain of PROM, can be a useful method for prediction of preterm labor. Bacterial role in the etiology of PROM has been suggested. The mother with PROM, also her neonate, might gain some benefit from this rapid tests and antibiotics treatment.
\end{abstract}

Key Words: Morbidity, mortality, neonatal sepsis, premature rupture of membrane

Received: 05 May 2018, Accepted: 09 June 2018

Corresponding Author: Ahmed M Abdelghany, Department of Obstetrics and Gynecology, Minia University, Minia, Egypt, Tel.: 0123927555,E-mail: drahmed_abdlghany@yahoo.com

ISSN: 2090-7265, August 2018, Vol.8, No.3

\section{INTRODUCTION}

Premature rupture of membrane (PROM), also called pre-labor rupture of membranes, is a condition that can happen in pregnancy. It is defined as rupture of membranes (amniotic sac breakage), ordinarily called breaking of the mother's water(s), more than 1 hour before labor onset ${ }^{[1]}$. It complicates about $2 \%$ of pregnancies but is linked to $40 \%$ of preterm deliveries and can give rise to significant neonatal morbidity and mortality ${ }^{[2]}$. Complications of PROM for both the fetus and newborn include fetal distress, altered pulmonary development, prematurity, cord compression and deformation ${ }^{[3]}$. The three reasons of neonatal death related to PROM are prematurity, pulmonary hypoplasia and sepsis. Woman with intrauterine infection usually deliver earlier than non-infected woman and infants born with sepsis have mortality about four times higher than those without neonatal sepsis. In addition, there are maternal threats associated with chorioamnionitis ${ }^{[4]}$. Causes of the rupture membrane are multiple, so the treatment may be difficult, as it is not directed to one identifiable factor. Infections are documented as one of the most important and possibly preventable causes of rupture membrane. They are thought to be responsible for about $50 \%$ of extreme preterm births of less than 28 weeks of gestation ${ }^{[5]}$. Infection is the single most common identifiable risk factor for PROM which can pass to the neonates during labour causing serious complication ${ }^{[6]}$. Bacterial infection was believed to be a key factor and lead to PROM by different pathways and mechanisms, in which the amniotic membrane is closely near to the endocervix ${ }^{[7]}$.

The microorganisms reach to the amniotic cavity through ascending, haematogenous or retrograde route and affect the amniotic cavity, leading to weakening of the membrane ${ }^{[8]}$. The aim of this study is to evaluate the bacterial causative organisms of premature rupture of membrane and its effect on maternal and neonatal outcome.

\section{PATIENTS AND METHODS}

This prospective cohort study which was conducted on 150 pregnant females at gestational age between 28 up to $\geq 39$ weeks at outpatient clinics, emergency room or inpatient departments in Minia University Hospital, presented with PROM, between January 2014 and 
December 2016. All patients were followed up from onset of PROM till two weeks after delivery. Ethical permission was sought from a Local Research Ethics Committee (REC). All patients consented for data retrieval for research purpose at time of admission after ensuring the confidentiality.

The study included pregnant patient diagnosed as PROM, primygravida and multigravida, pre-labour rupture of membrane $(<28$ week) up to term $(\geq 39$ weeks), and single-fetus pregnancy with cephalic presentation.

The exclusion criteria were: Uterine congenital anomalies, uterine fibroid, uterine hypoplasia, cervical incompetence or circulage, placenta previa, fetal distress (meconium), twins (Mechanical over-load), malpresentations, any contraindication of PV (cord prolapses, placenta abruption), and other medical problems (vaginal bleeding in pregnancy, proteinuria hypertension, intrauterine growth retardation, diabetes mellitus).

All patients were subjected to: (1) complete history taking;(2) general, abdominal and local vaginal examination; (3) routine investigations with stress on TLC / $48 \mathrm{~h}$ and $\mathrm{C}$ - reactive protein (CRP)/48h; (4) follow up fetal wellbeing by abdominal Ultrasound and CTG; and (5) high vaginal swab and amniotic fluid sample for culture and sensitivity.(6) All neonates are subjected to thorough general assessment and examination with special emphasis on prematurity, Apgar score, measurements, apparent congenital anomalies, signs of infection, respiratory morbidity and if neonate is in need for admission in neonatal intensive care unit or not.(7) Neonatal follow up in order to detect late complications

Suspected colonies were identified by direct microscopic examination using gram staining, Sudan III and catalase test. Patient was followed under conservative management with antibiotic course (Macrolides) till the result of culture and sensitivity is approved. Follow up of infection was done by collect serum TLC and CRP, in addition to clinical symptoms and signs. Patient with GA around (30-34) weeks undergo course of corticosteroid (Dexamethasone). Termination of pregnancy was occurred either by C.S or Induction of labor when gestational age $\geq 36$ weeks, or complication occurred. Two weeks after delivery, both mother and fetus were followed up to detect any complication of swab +ve sample.

The primary outcome measure was the prevalence of genital tract bacterial infection diagnosed via vaginal swab in premature rupture of membrane. The secondary outcome was fetal and maternal complication in swab +ve patients with PROM.
The statistical analysis of the data was performed by using SPSS 22 software package. Categorical data were presented as frequency and percent, and were compared by Chi-square test or Fisher exact test. Quantitative data were expressed as mean and $\mathrm{SD}$, and were compared by t-student test. $P$-valuewas assumed significant if less than 0.05 .

\section{RESULTS}

Demographic data and patient characteristics are presented in table (1). The mean age was $27.7 \pm 4.69$ years ranged between 19-38years old. The gestational age ranged between 28-39 weeks, with mean of $34.81 \pm 2.7$ weeks. Concerning parity, there was primigravida in 31 cases (24\%); however multigravida were 119 (76.3\%). History of abortion ranged between $0-1$.

Table 1: Demographic data and patient characteristics

\begin{tabular}{lc}
\hline $\begin{array}{c}\text { All patients } \\
(\mathrm{n}=150)\end{array}$ & Variables \\
\hline & Age \\
$(19-38)$ & Range \\
$27.76 \pm 4.69$ & Mean \pm SD \\
& Gestational Age \\
$(28-39)$ & Range \\
$34.81 \pm 2.7$ & Mean \pm SD \\
& Gestational Age \\
$33(22 \%)$ & $28-32$ \\
$78(52 \%)$ & $33-36$ \\
$39(26 \%)$ & $>36$ \\
& Gravidity \\
$(2-4)$ & Range \\
3 & Median \\
& Parity \\
$(1-2)$ & Range \\
1 & Median \\
& Abortion \\
$(0-1)$ & Range \\
0 & Median \\
\hline
\end{tabular}

The vaginal swabs of patients with PROM were positive in 90 patients $(60 \%)$ and negative in 60 patients (40\%). In 90 culture positive patients, the causative organisms were E. coli in 29 cases (19.3\%), followed by Group (B) Beta hemolytic Streptococci (Strept. Aglactiae) in 22 cases $(14.7 \%)$, Coagulase negative Staphylococci in 18 cases (12\%), Group (A) Beta hemolytic Streptococci (Strept. Pyogenes) in 12 cases $(8 \%)$ and Non-hemolytic streptococci in 9 cases (6\%) (Figure 1). 


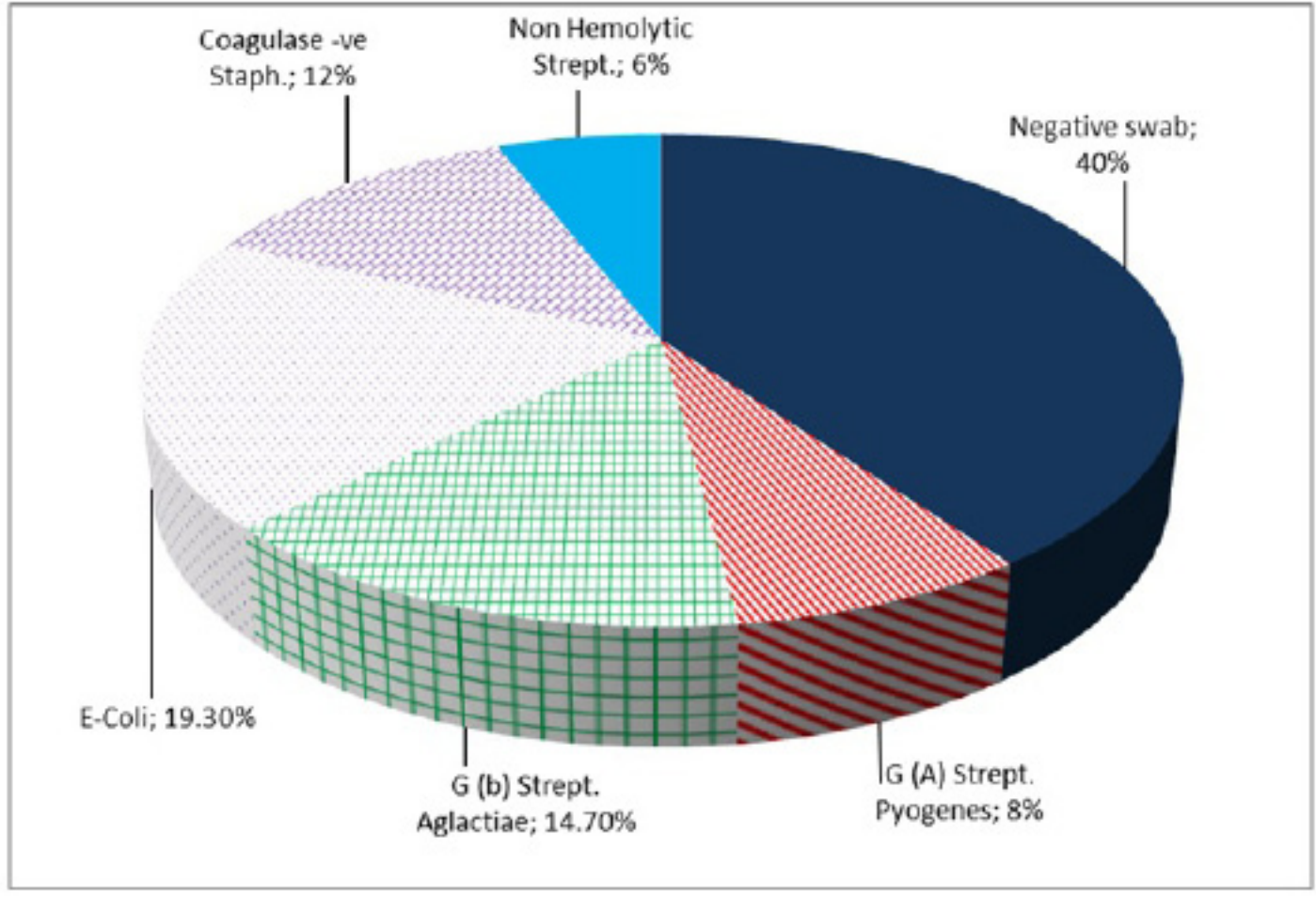

Fig. 1: Results of swab and causative organisms in positive swap cases.

Cases with chorioamnionits and puerperal sepsis all founded with + ve cultured swab and null with -ve swab cultured. There is a significant difference between the negative and the positive cases, the prevalence of maternal complication was higher in the positive swab result patients than the negative ones (Figure 2). Regarding the relation between fetal complication and cultured results presented
(Figure 3), there was a significant difference between the negative and the positive result cases in neonatal sepsis $(P$-value $=0.006)$, prematurity $(P$-value $=0.03)$ and END $(P$-value $=0.04)$, while the prevalence of IUFD and need for intubation was higher in positive swab results patient than negative swab results without significant difference.

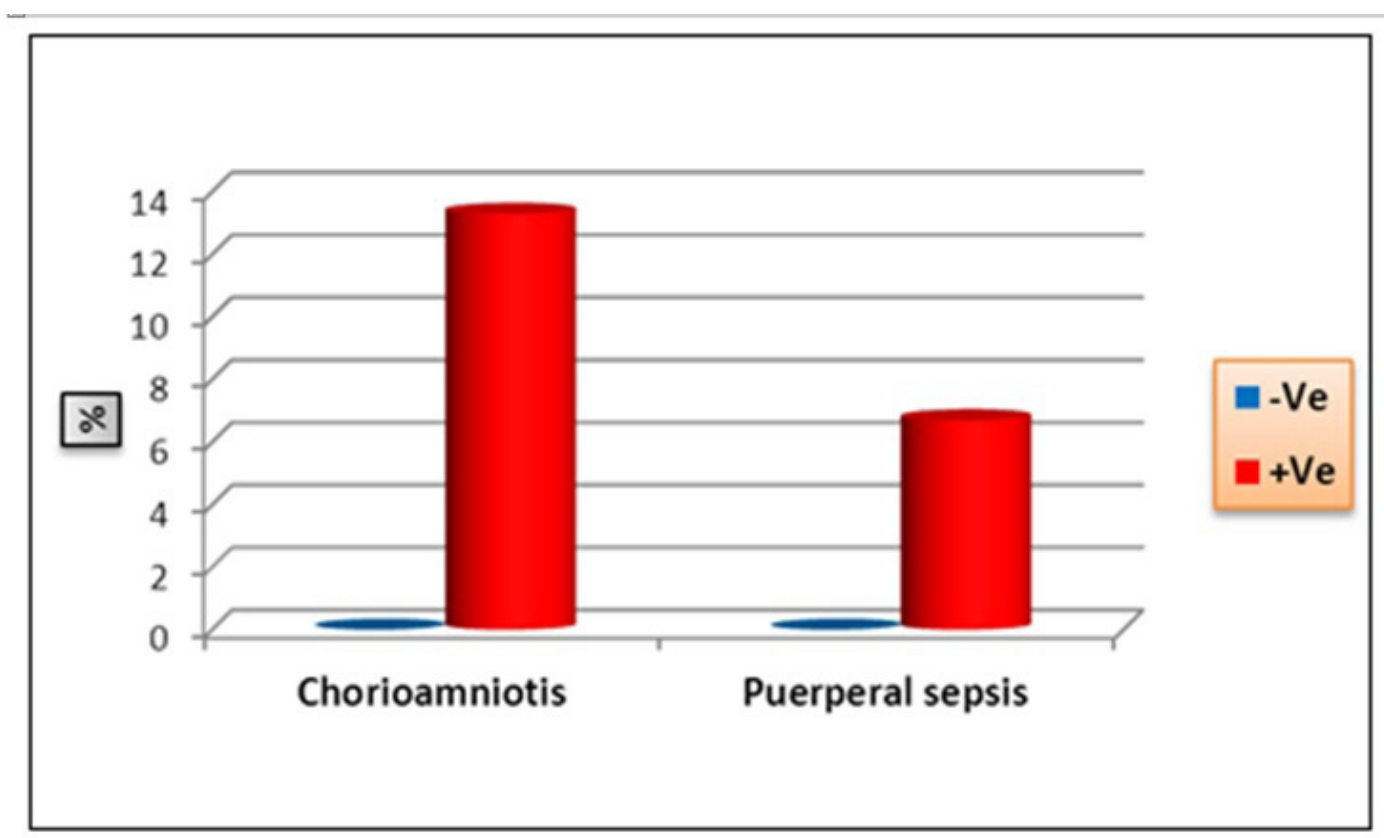

Fig. 2: Relation between maternal complication and culture result. 


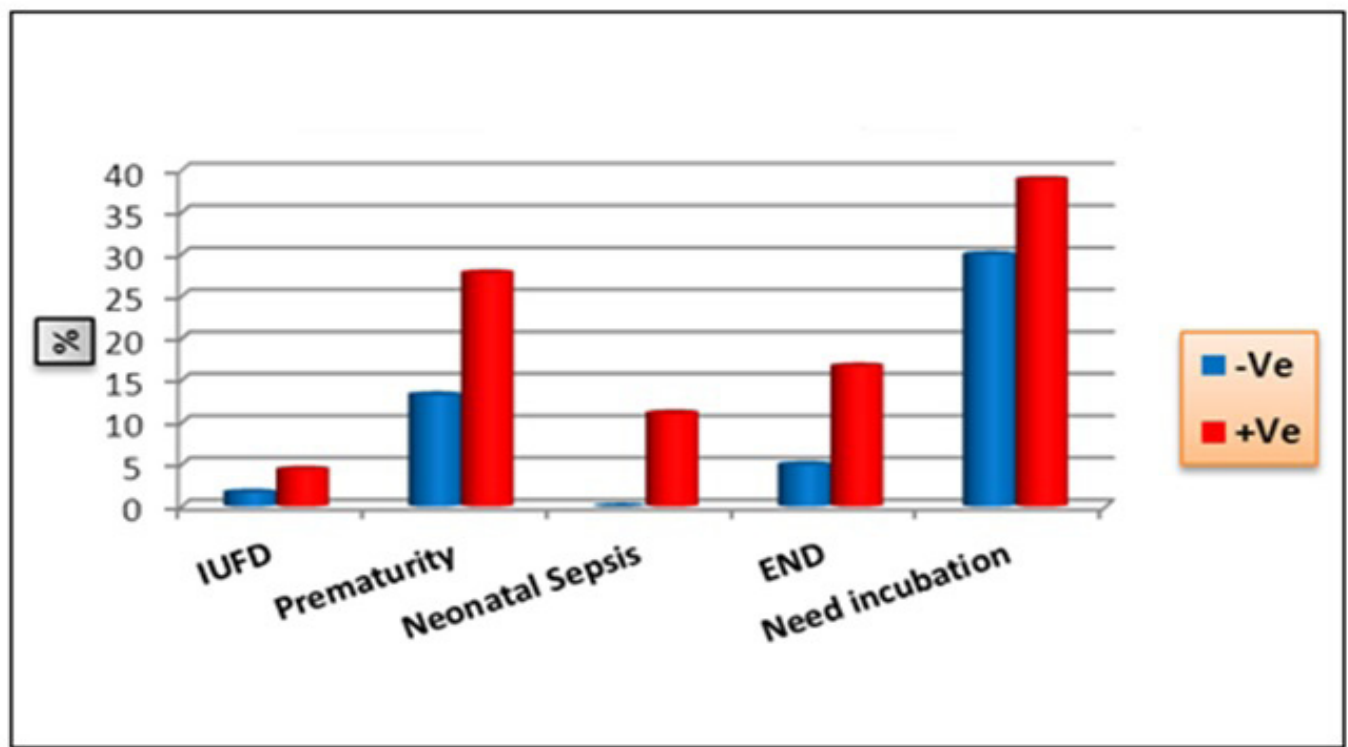

Fig. 3: Relation between fetal complications and culture results.

The relation between maternal complication and type of organisms presented in table (2), the most common organism founded in cultured swab of patients with Chorioamnionitis was G (B) Beta hemolytic streptococci in 8 out of 12 cases $(66.7 \%)$, while G(A) Beta hemolytic streptococci was founded in all cultured swab of patient who were developed puerperal sepsis. Table (3) represents the relation between fetal complication and type of organism founded in cultured swab + ve results. The most common organism founded in swab + ve cases with neonatal sepsis was Coagulase -ve Staph, in 3 out of 10 cases (30\%).G (b) StreptAglactiae was the common in premature cases 10 out of 25 cases $(40 \%)$. The most common organism founded in swab +ve cases incubated neonates was E-coli in 14 out of 35 cases $(40 \%)$. The most common organism founded in swab +ve cultured cases with END, was non hemolytic streptococci organism 5 out of 15 cases $(33.3 \%)$.

Table 2: Relation between maternal complications and the type of organism

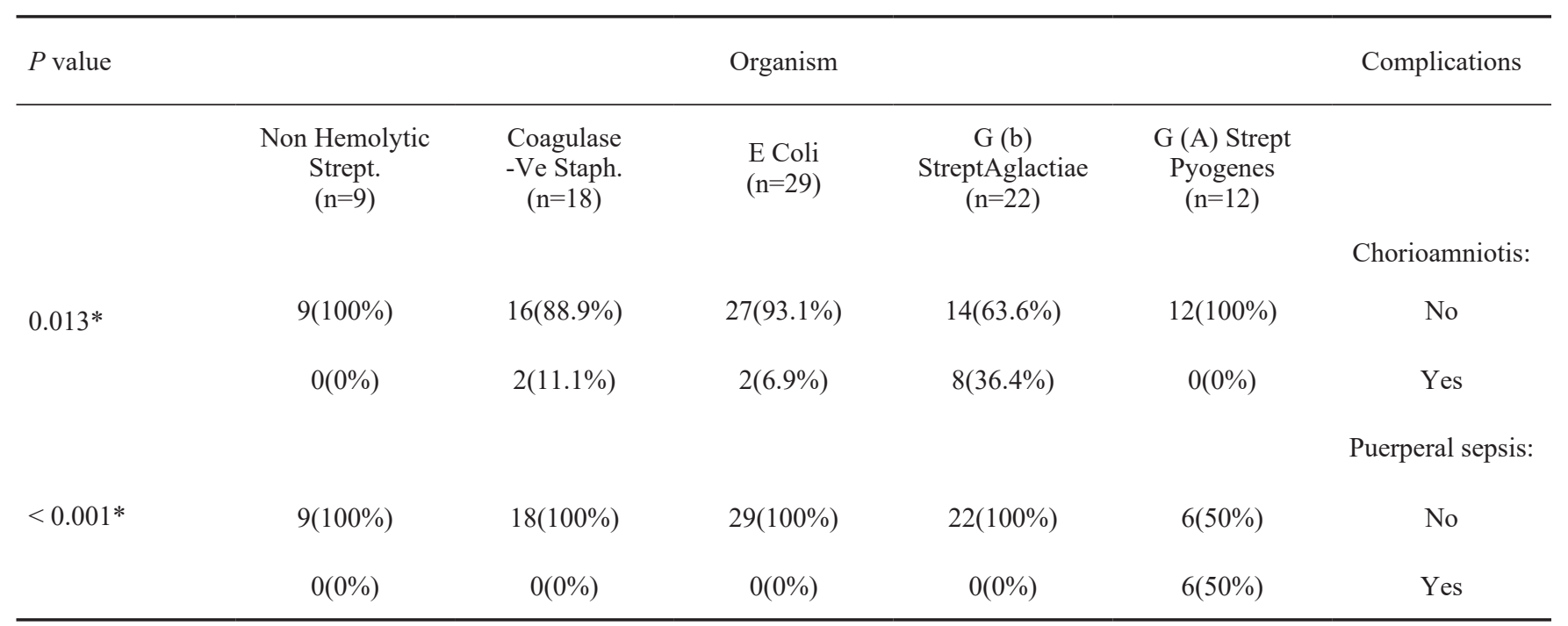

Fisher Exact or Chi-square test was used to compare qualitative data between the two groups.

*: significant difference at $p$ value $<0.05$ 
Table 3: Relation between fetal/neonatal complications and the type of organism

\begin{tabular}{|c|c|c|c|c|c|c|}
\hline$P$ value & & & Organisms & & & Complications \\
\hline & $\begin{array}{c}\text { Non Hemolytic } \\
\text { Strept. } \\
(n=9)\end{array}$ & $\begin{array}{l}\text { Coagulase } \\
\text {-Ve Staph. } \\
\quad(n=18)\end{array}$ & $\begin{array}{l}\text { E Coli } \\
(n=29)\end{array}$ & $\begin{array}{c}\mathrm{G}(\mathrm{b}) \\
\text { StreptAglactiae } \\
(\mathrm{n}=22)\end{array}$ & $\begin{array}{c}G(A) \text { Strept } \\
\text { Pyogenes } \\
(n=12)\end{array}$ & \\
\hline & & & & & & IUFD \\
\hline \multirow[t]{3}{*}{1} & $9(100 \%)$ & $17(94.4 \%)$ & $27(93.1 \%)$ & $21(95.5 \%)$ & $12(100 \%)$ & No \\
\hline & $0(0 \%)$ & $1(5.6 \%)$ & $2(6.9 \%)$ & $1(4.5 \%)$ & $0(0 \%)$ & Yes \\
\hline & & & & & & Prematurity \\
\hline \multirow[t]{3}{*}{$0.002 *$} & $3(33.3 \%)$ & $17(94.4 \%)$ & $22(75.9 \%)$ & $12(54.5 \%)$ & $11(91.7 \%)$ & No \\
\hline & $6(66.7 \%)$ & $1(5.6 \%)$ & $7(24.1 \%)$ & $10(45.5 \%)$ & $1(8.3 \%)$ & Yes \\
\hline & & & & & & Neonatal Sepsis \\
\hline \multirow[t]{3}{*}{$0.032 *$} & $9(100 \%)$ & $12(66.7 \%)$ & $26(89.7 \%)$ & $21(95.5 \%)$ & $12(100 \%)$ & No \\
\hline & $0(0 \%)$ & $6(33.3 \%)$ & $3(10.3 \%)$ & $1(4.5 \%)$ & $0(0 \%)$ & Yes \\
\hline & & & & & & END \\
\hline \multirow[t]{3}{*}{$0.020^{*}$} & $4(44.4 \%)$ & $16(88.9 \%)$ & $26(89.7 \%)$ & $18(81.9 \%)$ & 11(91.7\%) & No \\
\hline & $5(55.6 \%)$ & $2(11.1 \%)$ & $3(10.3 \%)$ & $4(18.1 \%)$ & $1(8.3 \%)$ & Yes \\
\hline & & & & & & \#Need incubation \\
\hline \multirow[t]{2}{*}{0.357} & $5(55.6 \%)$ & $14(77.8 \%)$ & $15(51.7 \%)$ & $15(68.2 \%)$ & $6(50 \%)$ & No \\
\hline & $4(44.4 \%)$ & $4(22.2 \%)$ & $14(48.3 \%)$ & $7(31.8 \%)$ & $6(50 \%)$ & Yes \\
\hline
\end{tabular}

Fisher Exact or Chi-square test was used to compare qualitative data between the two groups.

*: significant difference at $p$ value $<0.05$

\section{DISCUSSION}

Premature rupture of membranes (PROM) is associated with substantial perinatal morbidity and mortality and significant maternal morbidity ${ }^{[9]}$. It has been verified that many (25-30\%) of women with PPROM have a higher incidence of positive amniotic fluid culture attained by amniocentesis even when there is no clinical doubt for chorioamnionitis ${ }^{[10]}$. Early onset neonatal sepsis is considered as one of the most grave complications of PROM affecting the neonates, risk factors implicated in neonatal sepsis reveal the level of stress and illness experienced by the fetus at delivery, as well as the hazardous uterine environment surrounding the fetus before labour ${ }^{[11]}$. The ability to predict Early Onset Neonatal Infection is a great priority for physicians managing women with PROM, since it is the main cause of neonatal morbidity and mortality when PROM occurs at or after 24 weeks $^{[12]}$.

Our study demonstrated that $60 \%$ of mothers with PROM suffered from infection, $8 \%$ of them had chorioamnionitis and $6.7 \%$ of their neonates had neonatal sepsis, in agreement that chorioamnionitis after PROMwhich is one of the major risk factors of early onset neonatal sepsis- seems to be greater in hospitals caring for low socioeconomic population ${ }^{[13]}$.

In this study, the age, parity and gestational age of the included women didn't seem to have direct relation with the occurrence of PROM, as the age of the included cases ranged from 19 up to 38 years and parity ranged from G1PO up to G8P7, while gestational age ranged between 28-39 weeks without an increasing risk of PROM with certain age group or with increased parity, this is in agreement with $^{[14]}$, who proved that maternal age, parity and increase in maternal weight do not seem to cause PROM. All cases were of the same race and almost the same socioeconomic status, no history of smoking or drug abuse, to exclude the effects of these variables on the risk of preterm delivery ${ }^{[15]}$. All PROM women under the study were examined by taking sterile vaginal swabs immediately after admitted to the hospital (before tacking treatment), then follow up of the cases until delivery, assessment of the neonates then follow up of the neonates up to two weeks after delivery to detect whether any of them was incubated and to recognize the cause of incubation taking swabs from the septic foci of the neonates who suffered sepsis to correlate between the causative organisms of neonatal sepsis with that of their mothers with PROM. 
The results of vaginal swab revealed that the prevalence of bacterial infection in patients complaining of PROM was $60 \%$ (90 cases out of 150). Higher prevalence of bacterial infection among women with established PROM in literature ${ }^{[16,17]}$ agrees with our study, which reported a higher prevalence of Infection in pregnant women with established preterm labor than threatened. The mother with PROM might gain some benefit from rapid tests of vaginal infection and antibiotics treatment, as the vaginal infection testing is advocated in labor and delivery to recognize promptly this condition, and start therapy immediately ${ }^{[18]}$.

In our study, the most frequently isolated organisms from the maternal vaginal swabs were E-coli, followed by Group (B) Beta hemolytic streptococci, while the most common isolated organisms in swabs taken from the neonates with neonatal sepsis were Cagulase-Negative Staphylococcus organisms (Staph. Aureus), followed by E-coli.

The results of Arch Dis Child Fetal Neonatal Ed ${ }^{[19]}$ reported that the microorganisms most often implicated in neonatal sepsis in developing countries are different from those seen in developed countries, overall, Gram-negative organisms are more common and are mainly denoted by E-coli, Klebsiella sp., Pseudomonas and Salmonella ${ }^{[20]}$, of the Gram-positive organisms, Staphylococcus aureus, Coagulase negative streptococci, Streptococcus pneumoniae, and Streptococcus pyogenes are most commonly isolated ${ }^{[21]}$, while Beta haemolytic streptococci are generally rare in most of the African studies, the incidence is low with the exception of South Africa ${ }^{[22]}$.

It is not known whether those differences reflect true differences in pathogens across the world, reflecting an epidemiological transition in some countries or whether it reflects an epidemiological bias allied to the fact that most early onset sepsis neonates die at home before getting the health facilities and they do not appear in the statistics ${ }^{[6]}$.

The findings of our study suggested that screening of the vaginal infections in patients complain of PROM can be a useful method for prediction of preterm labor. It may guide in the risk assessment of pregnant women and in the decision of administration of antimicrobial treatment for the prevention of its complication.

\section{CONCLUSION}

Premature rupture of membranes (PROM) is associated with sizeable perinatal morbidity and mortality and significant maternal morbidity.

Our results suggest the role of bacteria in the etiology of PROM. The earlier the occurrence of PROM and the longer the interval between the rupture of fetal membranes and onset of labor, the more complications there are likely to happen. The mother with PROM might gain some benefit from this rapid tests and antibiotics treatment. It is useful to increase the size of study population to compare the results with other different studies.

\section{CONFLICT OF ITNEREST}

There are no conflicts of interest.

\section{ACKNOWLEDGMENT}

Authors thank Dr Ahmed A Saedii, lecturer of Clinical Pathology, Minia University for his help in laboratory workup done in this research.

\section{REFERENCES}

1. Gezer A, Parafit-Yalciner E, Guralp O, Yedigoz $\mathrm{V}$, Altinok T, Madazli R. Neonatal morbidity mortality outcomes in pre-term premature rupture of membranes. J Obstet Gynaecol. 2013;33(1):38-42.

2. Royal College of Obstetricians and Gynaecologists. Preterm Prelabour Rupture of Membranes. Greentop Guideline No. 44. November 2006 I Minor amendment, 2010.

3. Killbride HW, Thibealt DW. Neonatal complications of preterm premature rupture of membranes, pathophysiology and management. Clinics in Perinatology 2001; 28: 761-785

4. Royal College of Physicians of Ireland.Preterm prelabour rupture of the membranes (Pprom). Institute of Obstetricians and Gynaecologists. Version 1.0, Guideline No.24, April 2013.

5. Goepfert AR, Andrews WW, Carlo W, Ramsey PS, Cliver SP, Goldenberg RL, Hauth JC. Umbilical cord plasma interleukin-6 concentrations in preterm infants and risk of neonatal morbidity. Am J Obstet Gynecol. 2004;191(4):1375-81.

6. ACOG Committee on Practice BulletinsObstetrics. Clinical management guidelines for obstetriciangynecologists. (ACOG Practice Bulletin No. 80: premature rupture of membranes). Obstet Gynecol. 2007;109(4): 1007-19.

7. McClure EM, Dudley DJ, Reddy UM, Goldenberg RL. Infectious causes of stillbirth: a clinical perspective. ClinObstet Gynecol. 2010; 53(3): 635-45.

8. Gahwagi MMM, Busarira MO, Atia M. Premature Rupture of Membranes Characteristics, Determinants, and Outcomes of in Benghazi, Libya. Open Journal of Obstetrics and Gynecology 2015; 5: 494-504.

9. Obi SN, Ozumba BC. Pre-term premature rupture of fetal membranes: the dilemma of management 
in a developing nation. J ObstetGynaecol. 2007; 27(1): 37-40.

10. Strevens A, Moroy $\mathrm{P}$, Çakmak $\mathrm{P}$, Mungan $\mathrm{T}$, Mollamahmutoglu L, Danişman N. Insulin-like growth factor binding protein-1: a rapid detection of amniotic fluid leakage after amniocentesis. Turk J Med Sci. 2010; 35: 157-61.

11. Klinger G, Levy I, Sirota L, Boyko V, Reichman B, LernerGeva L 2009: Epidemiology and risk factors for early onset sepsis among very-lowbirth weight infants. Am J Obstet Gynecol. 2009; 201(1): 38.e1-6.

12. Levi M, Toh $\mathrm{CH}$. Guidelines for the diagnosis and management of disseminated intravascular coagulation. British Journal of Haematology 2009;145 (5): 24-33.

13. Osmanagaoglu MA, Unal S, Bozkaya H. Chorioamnionitis risk and neonatal outcome in preterm premature rupture of membranes. Arch Gynecol Obstet. 2005; 271(1): 33-9.

14. Modena AB, Kaihura C, Fieni S. Prelabour rupture of the membranes: recent evidence. Acta Biomed AteneoParmense 2004; 75(Suppl 2): 9-12.

15. Christiansen OB, Mathiesen O, Husth $\mathrm{M}$, Rasmussen $\mathrm{KL}$, Ingerslev $\mathrm{HJ}$, Lauritsen $\mathrm{JG}$, Grunnet N. Placebo-controlled trial of treatment of unexplained secondary recurrent spontaneous abortions and recurrent late spontaneous abortions with i.v. immunoglobulin. Hum Reprod.
1995; 10(10): 2690-5

16. Puapermpoonsiri S, Kato N, Watanabe K, Ueno $\mathrm{K}$, Chongsomchai C, Lumbiganon $\mathrm{P}$. Vaginal microflora associated with bacterial vaginosis in Japanese and Thai pregnant women. Clin Infect Dis. 1996; 23(4): 748-52.

17. Purwar M, Ughade S, Bhagat B, Agarwal V, Kulkarni $\mathrm{H}$. Bacterial vaginosis in early pregnancy and adverse pregnancy outcome. J ObstetGynaecol Res. 2001; 27(4): 175-81.

18. Myziuk L, Romanowski B, Johnson SC.BV Blue test for diagnosis of bacterial vaginosis. J ClinMicrobiol. 2003; 41: 1925-8.

19. Vergnano IM. The use of fluoroquinolones in children: recent advances. Expert Rev Anti Infect Ther. 2006; 4(5):853-60.

20. Noritomi DT, Soriano FG, Kellum JA. Metabolic acidosis in patients with severe sepsis and septic shock: a longitudinal quantitative study. Crit Care Med. 2009; 37(10): 2733-9.

21. Nizet V, Klein JO. Bacterial sepsis and meningitis. In: Infectious diseases of the Fetus and Newborn Infant, 7th ed, Remington JS, et al (eds.), Elsevier Saunders, Philadelphia, 2010. p. 222-275.

22. Harris DL, Weston PJ, Harding JE. Incidence of neonatal hypoglycemia in babies identified as at risk. J Pediatr. 2012; 161(5): 787-91. 